\title{
Rosa's roses: Reduced vowels in American English
}

\author{
Edward Flemming \\ Massachusetts Institute of Technology \\ Stephanie Johnson \\ Stanford University
}

\begin{abstract}
Beginning phonetics students are taught that American English has two contrasting reduced vowels, transcribed as [ə] and [i], illustrated by the unstressed vowels in the minimal pair Rosa's vs. roses. However little seems to be known about the precise nature or distribution of these vowels. This study explores these questions through acoustic analysis of reduced vowels in the speech of twelve American English speakers.

The results show that there is a fundamental distinction between the mid central [ə] vowel that can occur in unstressed word-final position (e.g. in Rosa), and high reduced vowels that occur in most other unstressed positions, and might be transcribed as [i]. The contrast between pairs like Rosa's and roses derives from this difference because the word-final [ə] is preserved when an inflectional suffix is added, so the schwa of Rosa's is similar to the final vowel of Rosa, whereas the unstressed vowel of roses is the high [i] reduced vowel quality found elsewhere. So the standard transcription of the reduced vowel contrast is justified, but the widespread use of [ə] to transcribe word-internal reduced vowels is misleading - mid reduced vowels are generally only found in stem-final position.
\end{abstract}

\section{Introduction}

It is well established that English exhibits a pattern of vowel reduction whereby vowel quality distinctions are neutralized in completely unstressed syllables. Some descriptions, e.g. Chomsky and Halle (1968:110ff.), imply that a 
single vowel quality is permitted in these positions, usually transcribed as schwa [ə]. So, for example, the first vowel of begin [bə'gin] and the final vowel of comma ['kamə] are both typically transcribed as [ə]. However, it is commonly observed in introductory phonetics courses that many accents of American English have two contrasting reduced vowels, usually illustrated by the minimal pair roses ['ıouziz] vs. Rosa's ['.ouzəz].

This minimal pair was noted by Trager and Bloch (1941:228), although they use [ə^] in place of the barred-i [i]. In the development of Trager and Bloch's analysis in Trager and Smith (1951) this transcription is replaced by the nowfamiliar barred-i (p.40). These transcriptions imply that both reduced vowels are central, but are distinguished by height. However I am not aware of any previous instrumental work that verifies these characterizations. There are also few clear generalizations about the distribution of these two reduced vowels, although Trager and Bloch (1941), Trager and Smith (1951) and Bronstein (1960:182) offer some observations. So it remains unclear whether the distinction between barred-i and schwa is a basic phonemic distinction of English, or whether it is limited to a restricted environment exemplified by pairs like roses-Rosa's. This experimental study aims to clarify the realization of these two reduced vowels, and to shed some light on their relative distributions.

Besides the general desire to supplement impressionistic observations with instrumental data, there is some reason to be sceptical about the standard 
characterization of the reduced vowels. Instrumental studies of schwa in British English (Kondo 1994) and Dutch (van Bergem 1995) have found that these vowels are generally high, although their precise quality is subject to considerable contextual variation. If English schwa is a high vowel, then how does it differ from the vowels that have been transcribed as barred-i?

We will see that the traditional characterization of the distinction between pairs like roses vs. Rosa's is reasonable: the unstressed vowel of roses is higher than the unstressed vowel of Rosa's, and both are central. However, the unstressed vowel of Rosa's differs from most word-internal unstressed vowels, such as the first vowel in begin [bə'gin], so it is misleading to transcribe both with the same symbol [ə]. The basic distinction is in fact between word-final schwa vowels, such as the final vowel in Rosa, and unstressed vowels in other positions: the word-final schwa vowels are lower than most non-final unstressed vowels. The distinction between schwa and barred-i is derived from this difference because the word-final schwa quality is approximately preserved when certain suffixes, including the possessive /-z/, are added. In other words, the unstressed vowel of Rosa's differs from the unstressed vowel of roses because the former is similar to a word-final schwa, whereas the latter has the usual non-final unstressed vowel quality. Accordingly, if a distinction is made between American English reduced vowels in transcription, it would be more appropriate to 
transcribe most non-final unstressed vowels with barred-i [i], and reserve schwa [ə] for word-final position.

The use of the schwa symbol to transcribe both the high reduced vowels in English (and other languages) and mid central vowels in languages like Bulgarian (Lehiste and Popov 1970) obscures an important distinction, and has led to misconceptions about the nature and typology of reduced vowels, as discussed in the conclusion ${ }^{1}$.

\section{Procedure}

\subsection{Materials}

To clarify the nature of the roses-Rosa's contrast, we recorded several minimal and near-minimal pairs of this form (1). The minimal pairs are constructed from pairs of words where one word ends with a sibilant fricative or

affricate, sibilant [s, z, $\left.\int, 3, \mathrm{t} \int, \mathrm{d} 3\right]$, as in rose ['Iouz], and the other word differs only by adding a final schwa, as in Rosa ['Iouzə]. Then the barred-i word is the plural of the sibilant-final word, e.g. roses, and the minimally-distinct schwa word is the possessive of the schwa-final word, i.e. Rosa's. The first word must end in a sibilant because the allomorph of the plural suffix that contains the barred-i only appears following a sibilant consonant. 
Pairs of this type are very rare in American English because familiar words that end with schwa are uncommon ${ }^{2}$, and ones that are minimally-distinct from sibilant-final words are even scarcer. Accordingly, two of the pairs are not fully minimal: ages-asia's and hinges-ninja's.

(1)

$\underline{\text { barred-i }}$

roses 'Jouziz

leases 'lisiz

rushes ' $\mathrm{I} \Lambda \int \mathrm{iz}$

ages 'eidziz

hinges 'hindziz schwa

Rosa's 'Jouzəz

Lisa's 'lisəz

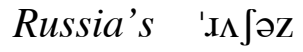

asia's 'eIzəz

ninja's 'nIndzəz

To obtain a broader sample of barred-i's and schwas in the same context, preceding word-final [z], we recorded five additional barred-i plurals (2) and five plurals of schwa-final words (3).

mazes
boxes
judge s
bushes
causes



(3) sofas
vodkas
sodas
alphas
umbrellas

Additional words were recorded to illustrate the quality of reduced vowels in word-final and word-medial positions for comparison with the prototypical examples of contrastive schwa and barred-i. Word-final schwa was exemplified by the stems of the possessives and plurals in (1) and (3):

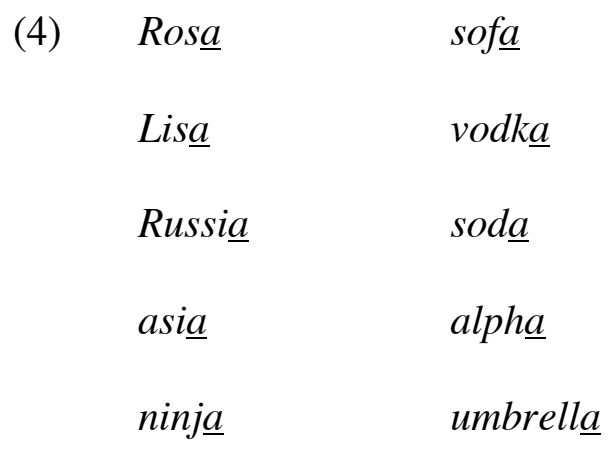

Ten further words exemplified non-final reduced vowels (5). The first five (5a) contain reduced vowels between coronals (alveolars and palato-alveolars) i.e. in segmental contexts similar to the reduced vowels in the minimal pairs - 
while the remaining five words contain reduced vowels adjacent to non-coronal consonants $(5 b)$.

(5) a. rhapsody

b. begin

$\begin{array}{ll}\text { suggest } & \text { report } \\ \text { suspend } & \text { compare } \\ \text { prejüdice } & \text { probable } \\ \text { today } & \text { suffocate }\end{array}$

Finally, we recorded a set of monosyllabic words containing a variety of full vowels in order to obtain a sense of the vowel spaces of the speakers (6).

\section{(6) $\quad$ Full vowels}

heed [i]

hid $\quad[\mathrm{I}]$

head $[\varepsilon]$

had [æ]

odd $\quad[\mathrm{a}]$

hood [v]

who $[\mathrm{u}]$ 
The words were read in the sentence frame 'Say __ to me'. The sentences were arranged in pseudo-random order, subject to the constraint that the two members of a minimal pair had to occur in different halves of the list. Filler items were added at the beginning and end of each page of the list. Each subject read each word twice. Subjects were recorded onto DAT tape in a sound attenuated room. The recordings were then downsampled to a sampling rate of $11025 \mathrm{~Hz}$ and transferred to a computer for acoustic analysis.

Subjects were recruited from the Stanford community. All were native speakers of English with no reported speech or hearing problems. Nine were female, and three were male.

\subsection{Analysis}

The frequencies of the first two formants of the reduced vowels were measured at the mid-point of the vowel using the formant analysis algorithm in the Praat acoustic analysis program, corrected by reference to FFT spectra where necessary. The word 'compare' frequently lacked any voiced vowel in the first syllable due to aspiration of the initial stop, so it was impossible to measure the first formant frequency, and these words were discarded from the analysis. Three further utterances had to be excluded because subjects mis-read the target word. 
Full vowels were measured using the same procedure, except that formants frequencies were measured where the formants remained level, or at extreme values (maxima or minima) of the formants.

\section{Results}

\subsection{Barred-i vs. schwa: Minimal pairs}

In the analysis we will only present data on the nine female speakers to minimize variation between speakers in overall formant ranges, but the results for the three male speakers are qualitatively similar.

A scatter plot of the first two formant frequencies of vowels from the minimal pairs for all female speakers are shown in figure 1, with the mean formant frequencies of the full vowels plotted to provide a frame of reference. The mean formant frequencies of barred-i, schwa, and the full vowels are also listed in tables 1 and 2.

Schwa has a higher mean F1 than barred-i (table 1), indicating that the schwa vowels are lower than the barred-i's, as implied by the standard transcriptions. The mean F1 of barred-i is similar to that of the lax high vowels [I] and [v], while the mean F1 of schwa is somewhat higher, with substantial variation ranging into mid-vowel territory. The mean F2 of schwa is slightly lower than the mean F2 of 
barred-i, so barred-i's tend to be more fronted. However, mean F2 of barred-i is still considerably lower than mean F2 of lax front [I] in hid $(2293 \mathrm{~Hz})$, so it is reasonable to describe most barred-i's as central vowels.

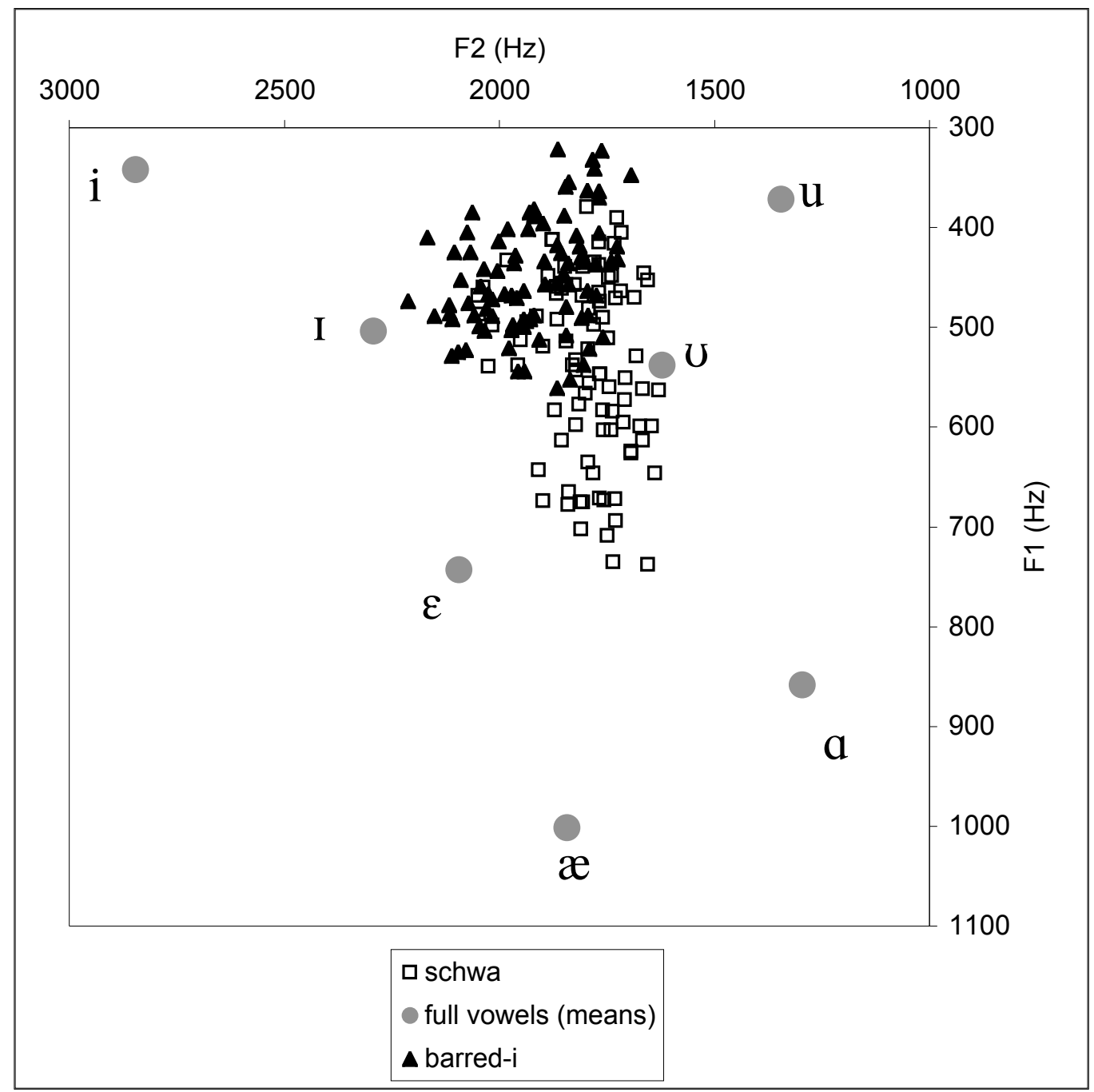

Fig. 1. Formant frequencies of all tokens of barred-i (filled triangles) and schwa (open squares) from the minimal pairs, and the mean formant frequencies of the full vowels (gray circles). 


\begin{tabular}{|c|c|c|}
\hline & F1 (s.d.) & F2 (s.d.) \\
\hline & $449 \quad(56)$ & $1922(121)$ \\
\hline $\mathrm{sc}$ & 539 (90) & 1797 \\
\hline
\end{tabular}

Table 1. Mean formant frequencies and standard deviations $(\mathrm{Hz})$ of barred$i$ and schwa vowels from the minimal pairs read by nine female speakers.

\begin{tabular}{lrr|rr} 
& F1 & (s.d.) & F2 & (s.d.) \\
\hline heed & 342 & $(36)$ & 2846 & $(103)$ \\
hid & 503 & $(66)$ & 2293 & $(94)$ \\
head & 743 & $(75)$ & 2094 & $(88)$ \\
had & 1002 & $(95)$ & 1843 & $(98)$ \\
odd & 858 & $(80)$ & 1296 & $(94)$ \\
hood & 538 & $(66)$ & 1623 & $(216)$ \\
who & 372 & $(37)$ & 1345 & $(274)$
\end{tabular}

Table 2. Mean formant frequencies and standard deviations $(\mathrm{Hz})$ of the full vowels, read by nine female speakers.

The significance of the differences in mean formant frequencies of barred-i and schwa was tested using ANOVA with effects VOWEL ('barred-i' or 'schwa'), PAIR, and SUBJECT (treated as a random effect) ${ }^{3}$. PAIR identifies the minimal pair that a word belongs to. It is not possible to distinguish the three-way interaction from the error term in a model of this kind, so the significance of this interaction cannot be tested (Raaijmakers et al 1999). The formant frequencies of the two repetitions of each word by a given speaker were averaged together for the analysis, yielding 90 observations altogether ( 9 speakers $\times 10$ words).

The results of the ANOVAs for F1 and F2 are summarized in tables 3 and 4. The difference in F1 between barred-i and schwa is significant $(p<0.01)$. There is 
also a significant interaction between VOWEL and SUBJECT, showing that the magnitude of the difference between barred-i and schwa varies across subjects, but mean F1 of barred-i is higher than mean F1 of schwa for all nine speakers.

\begin{tabular}{lrcl} 
Factor & $d f$ & $F$ & $p<F$ \\
\hline VOWEL & 1 & 53.7 & $0.0001^{* *}$ \\
SUBJECT & 8 & 13.8 & $0.006^{* *}$ \\
PAIR & 4 & 9.24 & $0.00^{* *}$ \\
SUBJECT $\times$ VOWEL & 8 & 2.55 & $0.03^{*}$ \\
SUBJECT $\times$ PAIR & 32 & 0.48 & 0.98 \\
VOWEL $\times$ PAIR & 4 & 2 & 0.12 \\
error & 32 & &
\end{tabular}

Table 3. Summary of ANOVA results for F1 $(\mathrm{N}=90)$. * significant at $p<$ $0.05, * *$ significant at $p<0.01$.

The difference in F2 between schwa and barred-i is also significant (table 4).

The interaction between VOWEL and SUBJECT is again significant - the difference in F2 is small for some speakers, although it is never reversed.

\begin{tabular}{lrcl} 
Factor & $d f$ & $F$ & $p<F$ \\
\hline VOWEL & 1 & 33.9 & $0.0004^{* *}$ \\
SUBJECT & 8 & 6.94 & $0.003^{* *}$ \\
PAIR & 4 & 8.04 & $0.0001^{* *}$ \\
SUBJECT $\times$ VOWEL & 8 & 5.34 & $0.0003^{* *}$ \\
SUBJECT $\times$ PAIR & 32 & 1.68 & 0.07 \\
VOWEL $\times$ PAIR & 4 & 0.42 & 0.80 \\
error & 32 & &
\end{tabular}

Table 4. Summary of ANOVA results for F2 $(\mathrm{N}=90)$. * significant at $p<$ $0.05, * *$ significant at $p<0.01$. 
In summary, the traditional characterization of the distinction between barred-i and schwa in pairs like roses-Rosa's is reasonable: barred-i in these words is high, schwa is generally lower, and both are central.

\subsection{Other examples of schwa and barred-i}

The reduced vowels from plurals of schwa-final words (e.g. sofas) have similar formant frequencies to the vowels in possessives of schwa-final words (e.g. Ros $\underline{\text { 's) }}$ ) as shown by the scatter plot in figure 2. This supports the practice of transcribing both as schwa, and suggests that the schwa vowels observed in the minimal pairs are not atypical for this segmental context. The reduced vowels in the additional plurals (2) are also very similar to the barred-i's observed in the minimal pairs (figure 3). Table 5 lists the mean formant frequencies for schwa in possessives and plurals (combined), barred-i, and non-final unstressed vowels. 


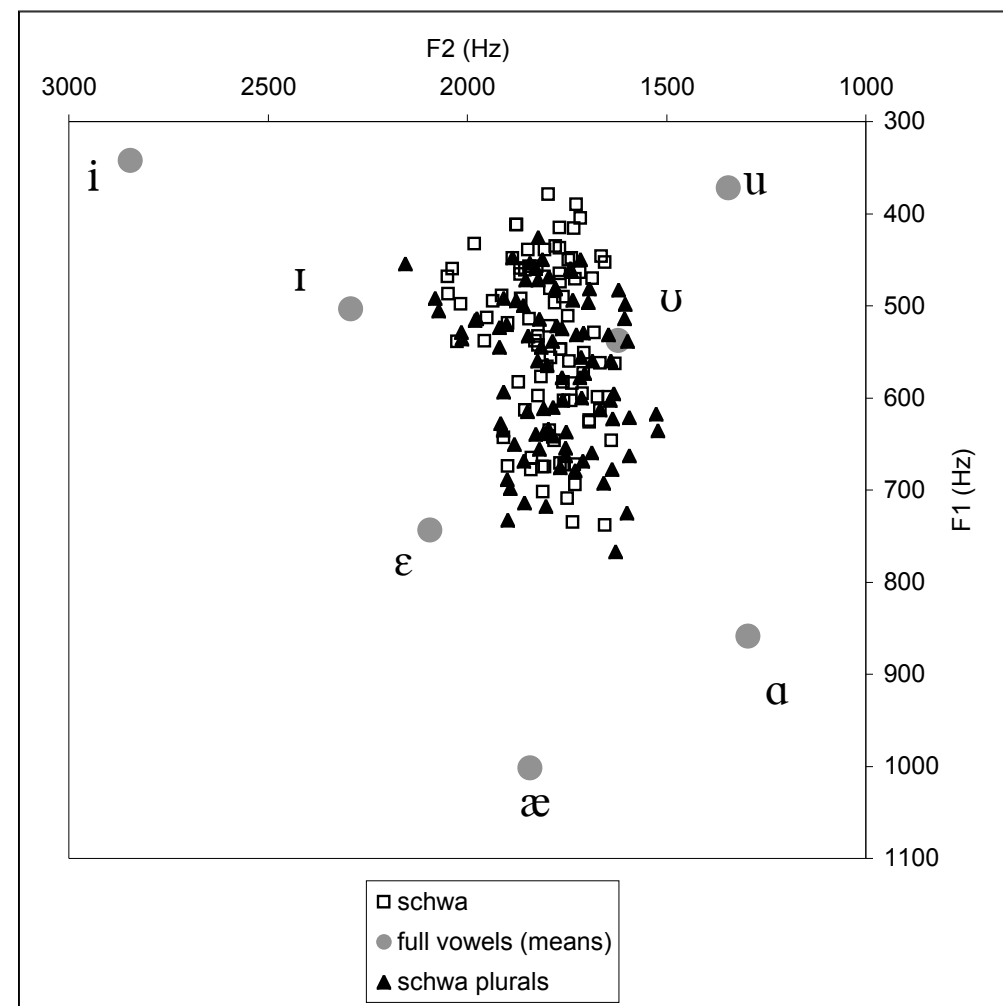

Fig. 2. Formant frequencies of all tokens of schwa from the possessive forms in the minimal pairs (open squares) and the plurals of schwa-final words (filled triangles). 


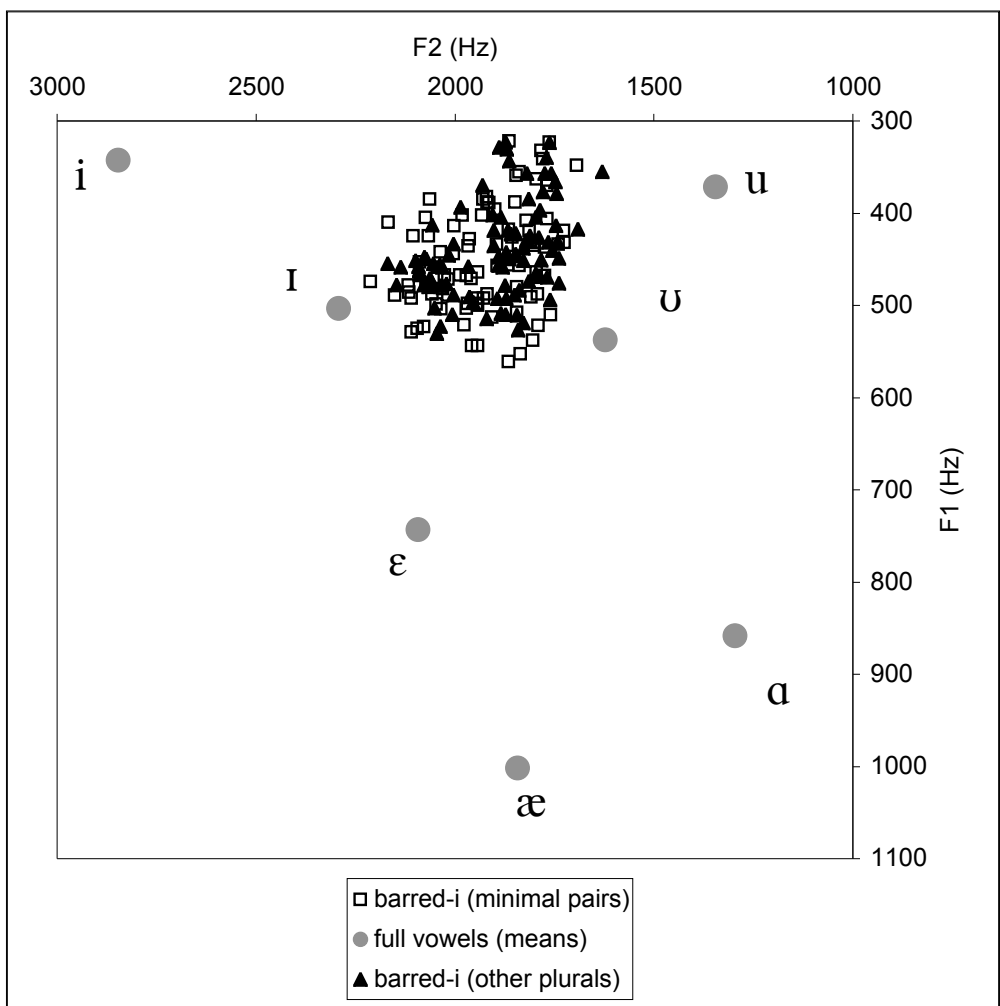

Fig. 3. Formant frequencies of all tokens of schwa from the possessive forms in the minimal pairs (open squares) and the plurals of schwa-final words (filled triangles).

\begin{tabular}{|c|c|c|c|}
\hline & examples & F1 (s.d.) & F2 (s.d.) \\
\hline schwa (plural/poss.) & Ros $\underline{a}^{\prime} s$, sofas & $556 \quad(88)$ & $1791 \quad(112)$ \\
\hline barred-i & roses & $446 \quad(54)$ & 1912 (123) \\
\hline \multicolumn{4}{|c|}{ non-final reduced vowels: } \\
\hline all & begin & (83) & $1829 \quad(564)$ \\
\hline coronal context & suggest & (52) & 2042 (177) \\
\hline final schwa & soda & $(115)$ & 1772 (138) \\
\hline
\end{tabular}

Table 5. Mean formant frequencies and standard deviations $(\mathrm{Hz})$. 


\subsection{Non-final reduced vowels}

Figure 4 shows a scatterplot of the unstressed reduced vowels from non-final positions (e.g. begin, suggest), plotted together with the barred-i's from the minimal pairs for comparison. It can be seen that the non-final reduced vowels cover a much wider range of F2 frequencies than the reference barred-i's, but in F1 they are quite comparable in mean and standard deviation, and tend to have lower F1 than schwa (table 5).

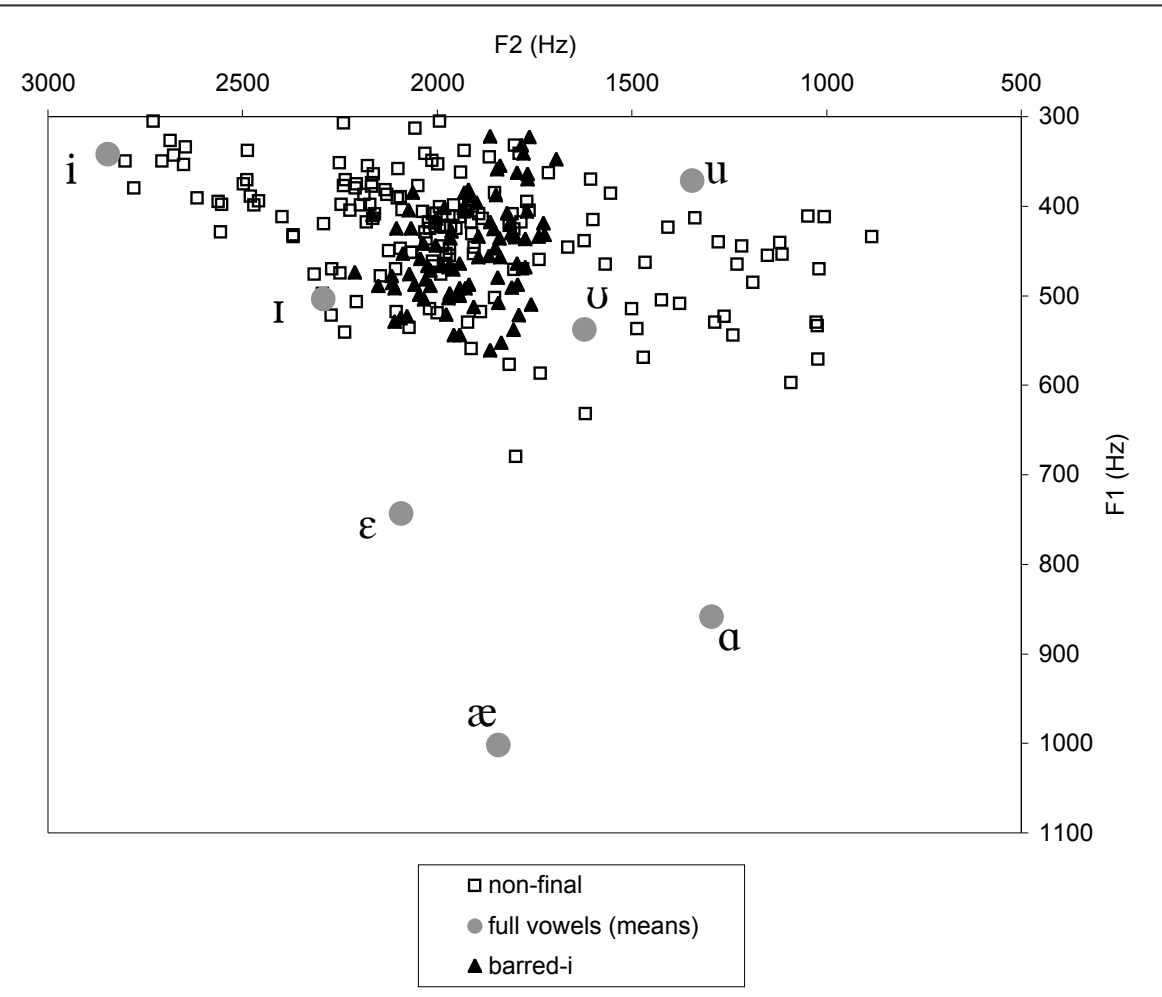

Fig. 4. Formant frequencies of all tokens of non-final reduced vowels (open squares) and barred-i from minimal pairs (filled triangles). 
The great variation in F2 is due to the fact that F2 in reduced vowels is highly dependent on the segmental context (Kondo 1994, cf. van Bergem 1995 on Dutch schwa), and the medial unstressed vowels appear in a much greater variety of contexts than the barred-i's found in plurals. Extremely low F2s are observed in the reduced vowel of probable (mean $1159 \mathrm{~Hz}$ ), where the preceding vowel is back $[a]$, the following syllable contains a strongly velarized lateral, and the surrounding consonants are labials so the lips are probably never fully opened during the reduced vowel. High F2 is observed in the reduced vowel of 'begin', presumably due to the following velar which is fronted in the context of the following front vowel [I].

The barred-i's plotted in figure 4 all appear between coronal fricatives, so the most comparable medial reduced vowels are those that appear between coronal consonants. Just these medial reduced vowels are plotted in figure 5, with the barred-i's for comparison. It can be seen that the formant frequencies are very similar, although the medial reduced vowels range into higher values of F2, particularly adjacent to a palato-alveolar as in suggest and prejüdice. Consequently it seems likely that the barred-i found in words like roses is essentially the same as other non-final reduced vowels - that is, a high vowel, with backness and rounding (and hence F2) dependent on segmental context - and both are distinct from schwa as observed in words like Rosa's. 


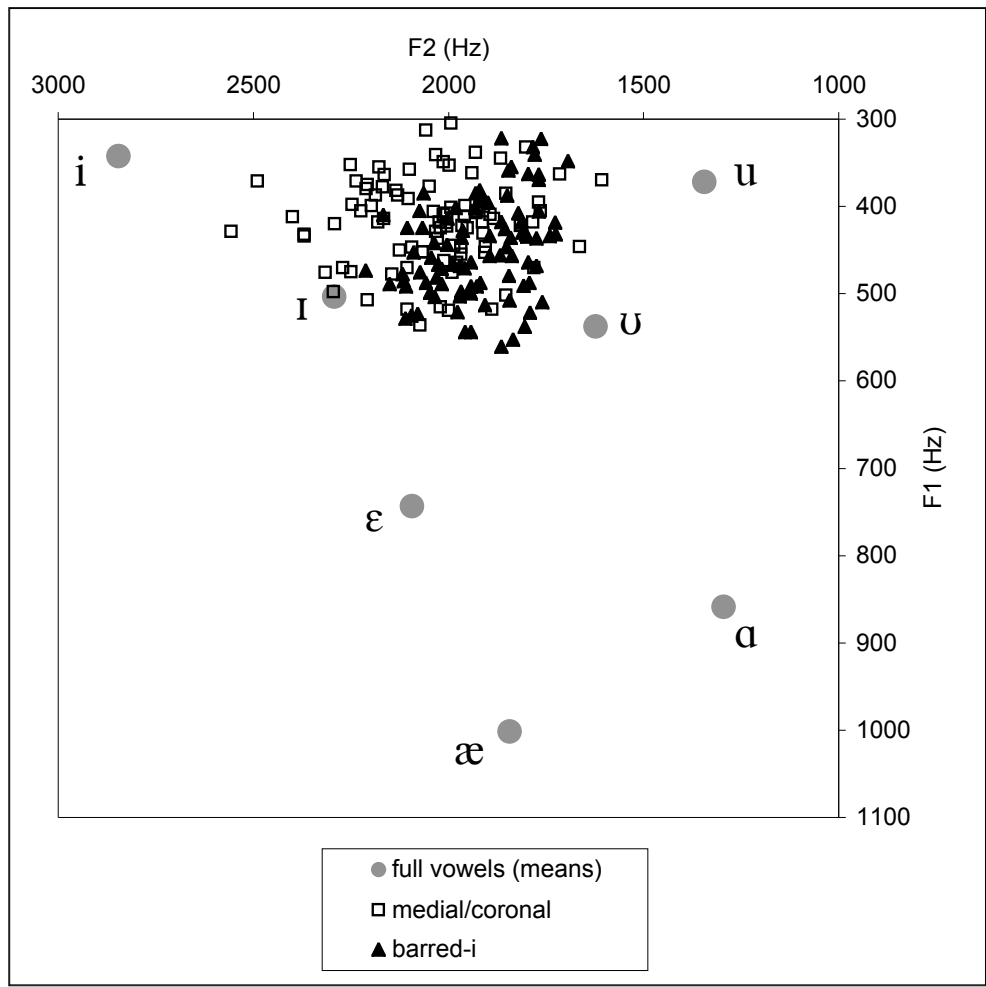

Fig. 5. Formant frequencies of non-final reduced vowels from coronal contexts (open squares) and barred-i from minimal pairs (filled triangles).

\subsection{Final schwas}

The mean F1 of unsuffixed final schwa (e.g. Rosa) is even higher than in the possessives or plurals of these words (Rosa's, sofas) (see table 5). Figure 6 shows that $\mathrm{F} 1$ of word final schwa varies across a wide range, extending to the vicinity of low vowels, although the mean of $659 \mathrm{~Hz}$ indicates a mid vowel. 


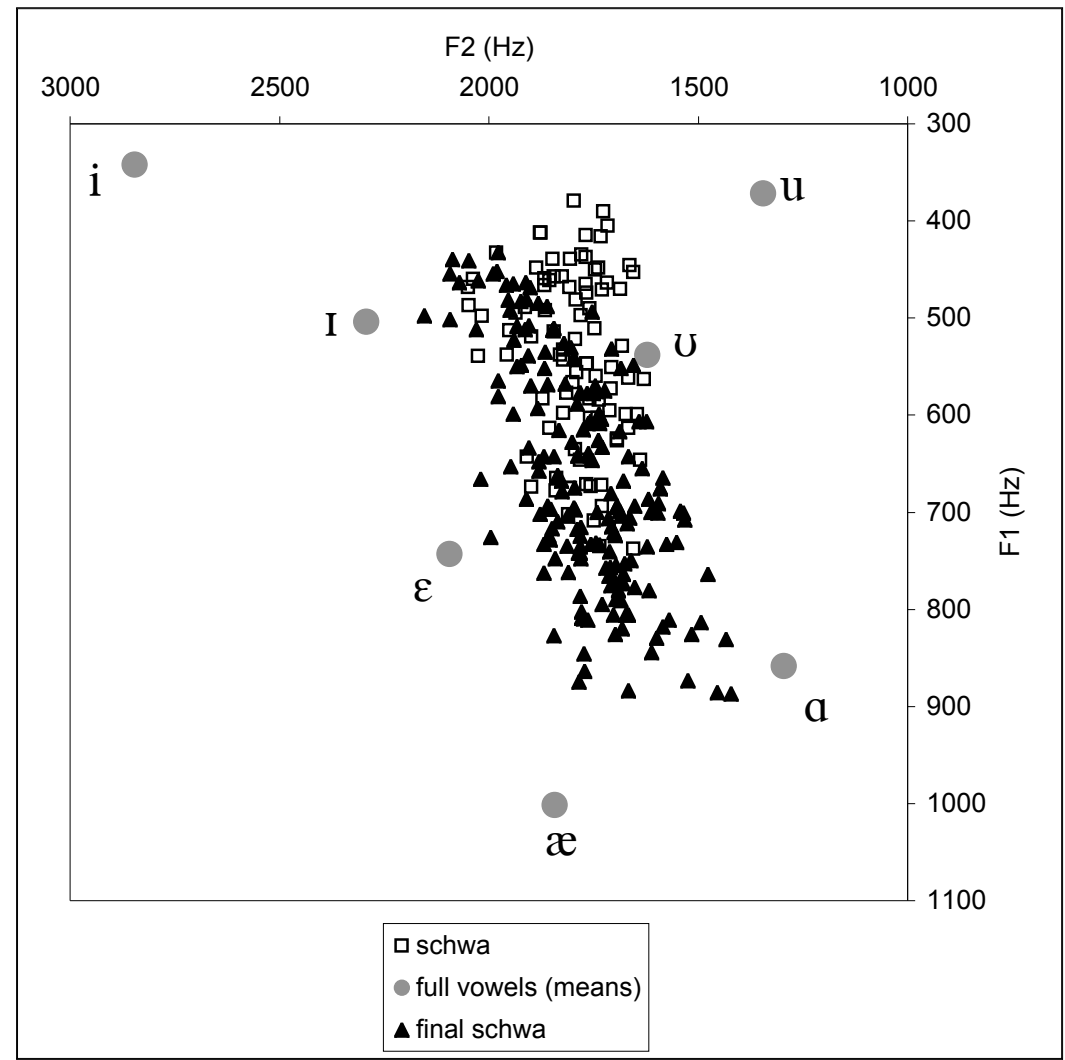

Fig. 5. Formant frequencies of schwa from minimal pairs (open squares) and word-final schwa (filled triangles).

\section{Discussion}

This study of reduced vowels reveals a fundamental distinction between word-final schwa and other reduced vowels: word-final schwas center around a mid vowel quality, while reduced vowels in other positions are generally high. This suggests that the minimal contrast in pairs like roses-Rosa's arises because 
the word-final vowel quality of Rosa is partially preserved on the addition of an inflectional suffix such as the possessive /-z/, while the reduced vowel in roses is the usual high, centralized vowel quality found in non-final unstressed vowels.

The difference between final and non-final reduced vowels can be related to differences between the unstressed vowel systems in these positions. While nonfinal schwa is not in contrast with other unstressed vowel qualities, there are four contrasting unstressed vowel qualities in word-final position: /i, ə, ov/, and the rhotic vowel /or (Hayes 1995:14f.) (7). The fact that all the final vowels in (7) are preceded by flaps provides evidence that they are in fact completely unstressed, since flapping only applies before unstressed vowels (Kahn 1976). This diagnostic indicates that full vowels in non-final position receive at least secondary stress (with a few systematic exceptions discussed below), so forms like *['pıourin] (cf. protein ['p $\left.{ }^{\mathrm{h}} \mathrm{\jmath o \mho}, \mathrm{tin}\right]$ ) and *['manəroun] (cf. monotone ['manə,toun]) are ill-formed.

$\begin{array}{ll}\text { 'p.Iri } & \text { pretty } \\ \text { 'beirə } & \text { beta } \\ \text { 'marou } & \text { motto } \\ \text { 'lerə } & \text { letter }\end{array}$


Given the three-way contrast between non-rhotic vowels, the fact that final schwa is non-high serves to keep it distinct from /i, ov/. In the absence of contrast, reduced vowels can be realized as high without endangering any contrasts. Under these circumstances, high vowels are generally preferred because they require minimal opening of the constricted vocal tract required for adjacent consonants (van Bergem 1994, Flemming 2004).

Note that unstressed vowels other than those usually transcribed as schwa [ə] can appear in non-final unstressed positions but they do not minimally contrast with schwa. Hayes (1995:14f.) observes that American dialects allow [I] to appear in unstressed syllables preceding the velar nasal [n], as indicated by the appearance of flaps in words like Keating ['khirı]], and [i] and [ov] can occur unstressed before vowels (e.g. Whittier ['wirio'], Ottawa ['arovə]) (cf. Liberman and Prince 1977:272f.). However schwa does not occur in either context and so does not contrast with these other unstressed vowel qualities. The sequence [ju] or [jo] also appears in unstressed syllables in words like argument ['agjumənt] and occupation [akju'per $\left.\int_{1}\right]^{4}$. Flapping is not applicable as a diagnostic of lack of stress in this case since flapping does not apply before glides, but a light syllable preceding the primary stress cannot be stressed (e.g. Liberman and Prince 1977, Hayes 1981), so it is safe to say that the second syllable of occupation lacks stress. Again, there is no minimal contrast with schwa. In fact unstressed [ju] is in free variation with [jə] (e.g. [akjə'per $\left.\left.\int \mathrm{n}\right]\right)$. 
These observations raise questions as to why these vowel qualities appear in these particular contexts. The feasibility of a pre-vocalic contrast between unstressed $/ \mathrm{i} /$ and $/ \mathrm{ov} / \mathrm{can}$ be seen as related to the presence of intervocalic glides in these sequences. That is phonetic glides similar to [j] and [w] appear in sequences of $/ \mathrm{iV} /$ and $/ \mathrm{ov} \mathrm{V} /$ respectively, making it possible to realize a larger and longer difference in the formants of the two vowels than would normally be possible in a non-final unstressed vowel. The basis for the occurrence of unstressed [I] in [II] is less clear. In the study of non-final schwas we observed that F2 of these vowels is strongly dependent on segmental context, so it is possible that the observed [I] results from assimilation to the following velar nasal.

The preservation of word-final schwa quality in suffixed words like Rosa's and sofas fits into a more general pattern: all word-final unstressed vowel qualities are preserved under affixation of the plural or possessive suffix, so ['srriz] cities preserves the unstressed tense [i] that otherwise only appears in word-final position, and the same applies to the [or] of ['marouz] mottoes. So the minimal contrast between barred-i and schwa in pairs like roses-Rosa's can only arise because of the difference in morphological structure between the two words: in roses the stem boundary precedes the reduced vowel, [[.rouz]iz], while in Rosa's it follows it, [[.rouzə]z]. This contrast does not arise in other contexts, such as within monomorphemic words. 
It would be interesting to investigate the same issues in English Received Pronunciation (RP) because impressionistic descriptions of this accent suggest that it may differ in interesting ways from the American English accents described here. First, the distinction between pairs like Rosa's and roses is usually transcribed in terms of a difference between [ə] and [I] - that is, the vowel of the unstressed syllable of roses is identified with the stressed vowel quality found in words like kit. Second, a similar distinction is claimed to be possible in non-final unstressed syllables. Wells (1982:167f.) argues that RP and other English dialects distinguish unstressed [I] and [ə] in pairs such as Lenin [lenIn] vs. Lennon [lenən], and rabbit [..æbit] vs. abbot [æbət] (Wells's transcriptions). This distinction is not made in the American accents that we are familiar with, so Lenin and Lennon are homophonous, for example.

Our impression is that RP has a difference in height between word-final and non-final unstressed vowels, and that the unstressed vowel in words like Rosa's approximates the word final schwa quality as in American English. Experimental investigation is required to determine if the unstressed vowel of words like roses is in fact comparable to stressed [I] and thus a more fronted vowel than in American English. As for the existence of a word-internal contrast between unstressed [I] and [ə], it is difficult to be certain whether the second syllables of Lenin and rabbit are really unstressed or actually bear secondary stress since secondary stress is possible in a final closed syllable, as in words like gymnast 
['d3ım,næst] and proton ['ph ${ }^{\mathrm{h}}$ IOU,ton] (Hayes 1981, Ross 1972). One possible indication that [I] bears some stress in Lenin is the fact /In/ in comparable contexts cannot be realized as a syllabic nasal, whereas /ən/ is often realized as a syllabic nasal - compare latin ['læetın] and satin ['sætın] to button ['bstn] and cotton [' $\mathrm{k}^{\mathrm{h}} \mathrm{ptn}$ ]. In any case, preliminary investigation of two speakers who make this distinction suggests that the contrast is primarily in F2 - Lenin has a front vowel while Lennon has a central vowel, but both vowels are relatively high, so the contrast would be better transcribed as ['lenin] vs. ['lenin]. So this contrast probably differs from that found in roses vs. Rosa's, but experimental investigation is warranted.

The results of this study also show that the common practice of transcribing most medial and final unstressed vowels as [ə] while distinguishing certain suffix unstressed vowels as [i] is misleading. We have seen that the basic distinction is between word-final reduced vowels, and all other reduced vowels including the vowel of the plural suffix, so it would be more accurate to transcribe all vowels in the latter class as [i] while reserving [ə] for stem-final reduced vowels as in Rosa and Rosa's.

This is not simply a question of accuracy in transcription. The use of [ə] to transcribe non-final reduced vowels has lead to the myth that these vowels are 
mid since schwa is conventionally classified as a mid central vowel, but non-final reduced vowels are in fact generally high, as shown by the present study and by Kondo (1994). The failure to distinguish between high and mid reduced vowels has lead to confusions and misconceptions regarding the typology of reduced vowels. A contextually variable high vowel is also the result of vowel reduction in Dutch in most contexts (van Bergem 1994), suggesting that this type of vowel may be typical in contexts where all vowel quality contrasts are neutralized. Mid central schwa, on the other hand, only seems to arise in contrast with high vowels, as in word-final position in English. For example reduced vowel inventories of the general form [i, ə, u] occur in unstressed syllables in Russian ${ }^{5}$ (Padgett and Tabain 2003), Bulgarian (Lehiste and Popov 1970), and in final unstressed syllables in Brazilian Portuguese (Mattoso Camara 1972). Mid central vowels are also found in stressed vowel systems, as in Bulgarian and some Balearic dialects of Catalan (Herrick 2003). Failure to distinguish reduced vowels of the English type from true mid central vowels obscures generalizations of this kind.

\section{Acknowledgements}

We would like to thank visitors to our poster at the $147^{\text {th }}$ meeting of the ASA in New York and two anonymous reviewers for helpful comments and questions. 


\section{References}

BOOIJ, G. (1995). The Phonology of Dutch. Oxford: Oxford University Press.

BRONSTEIN, A.J. (1960). The Pronunciation of American English. New York: Appleton-Century-Crofts.

CHOMSKY, N. \& HALLE, M. (1968). The Sound Pattern of English. New York:

Harper and Row.

FLEMMING, E. (2004). Contrast and perceptual distinctiveness. Hayes, B.,

Kirchner, R. \& Steriade, D. (eds.) Phonetically-Based Phonology, 232-276.

Cambridge: Cambridge University Press.

HAYES, B. (1981). A Metrical Theory of Stress Rules. Indiana University Linguistics Club, Bloomington, Indiana.

HAYES, B. (1995). Metrical Stress Theory: Principles and Case Studies. Chicago: University of Chicago Press.

HERRICK, D. (2003). An Acoustic Analysis of Phonological Vowel Reduction in Six Varieties of Catalan. Ph.D. dissertation, University of California, Santa Cruz.

KAHN, D. (1976). Syllable-Based Generalizations in English Phonology. Ph.D. dissertation, Massachusetts Institute of Technology, Cambridge, Massachusetts. 
KONDO, Y. (1994). Targetless schwa: is that how we get the impression of stress timing in English? Proceedings of the Edinburgh Linguistics Department Conference '94, 63-76.

LADEFOGED, P.N. (1993). A Course in Phonetics. Second edition. Fort Worth, Texas: Harcourt Brace Jovanovich.

LEHISTE, I. \& POPOV, K. (1970). Akustiche Analyse bulgarischer Silbenkerne. Phonetica 21, 40-48.

LIBERMAN, M.Y. \& PRINCE, A. (1977). On stress and linguistic rhythm. Linguistic Inquiry 8, 249-336.

MATTOSO CAMARA, J. (1972). The Portuguese Language. Chicago: University of Chicago Press.

PADGETT, J. \& TABAIN, M. (2004). Adaptive dispersion theory and phonological vowel reduction in Russian. To appear in Phonetica.

RAAIJMAKERS, J.G.W., SCHRIJNEMAKERS, J.M.C. \& GREMMEN, F. (1999). How to deal with "the language-as-fixed-effect fallacy": Common misconceptions and alternative solutions. Journal of Memory and Language $41,416-426$.

ROSS, J.R. (1972). A reanalysis of English word stress (part 1). Brame, M.K. (ed.) Contributions to Generative Phonology. Austin: University of Texas Press. 
TRAGER, G.L. \& BLOCH, B. (1941). The syllabic phonemes of English.

Language 17, 223-246.

TRAGER, G.L. \& SMITH, H.L. (1951). An Outline of English Structure. Studies

in Linguistics: Occasional Papers 3. Norman, Oklahoma: Battenburg Press.

VAN BERGEM, D.R. (1994). A model of coarticulatory effects on the schwa.

Speech Communication 14, 143-162.

WELLS, J.C. (1982). Accents of English I: An Introduction. Cambridge:

Cambridge University Press.

${ }^{1}$ A similar contrast between pairs like Rosa's and roses is observed in English Received Pronunciation (RP), and other English accents, but the unstressed vowel of words like roses is traditionally transcribed as [I] identifying it with the vowel of pin. It remains to be seen whether this is primarily a difference of convention, or if it reflects a significant phonetic difference.

${ }^{2}$ Schwa-final words are plentiful in non-rhotic accents, such as English Received Pronunciation, because they have developed from words with unstressed final rhotic vowels. All of our subjects spoke rhotic varieties.

${ }^{3}$ It is not necessary to treat PAIR as a random effect, since the members of each pair are matched with respect to properties that are likely to affect formants of the target vowels since they are near-minimal pairs (Raaijmakers et al 1999).

${ }^{4}$ Thanks to an anonymous reviewer for bringing this to my attention. The same reviewer suggests that [u] can occur unstressed in the first syllable of July and in the second syllable of $i s s u e$. I would analyze both [u] vowels as bearing secondary stress (flapping does not apply before [u] in American English even in words like tutui and manitou). There is an alternative pronunciation of July with an unstressed initial syllable, but in this case the first vowel is reduced: [dzəlar].

5 According to standard descriptions, the system is $[i, \mathfrak{e}, \mathrm{u}]$ in the syllable immediately preceding stress - i.e. the 'schwa' vowel is lower-mid in this position. Padgett and Tabain (2003) find some evidence in support of this claim in their acoustic study. 